\title{
Evolving from Clinical to Positive Psychology: Understanding and Measuring Patients' Strengths: A Pilot Study
}

\author{
Tanja Bellier-Teichmann • Valentino Pomini
}

Published online: 22 October 2014

(C) Springer Science+Business Media New York 2014

\begin{abstract}
Empirical evidence suggests that concentrating on patients' internal and external strengths serves a preventative function against psychopathology. However, standardized tools assessing strengths of patients suffering from mental disorders are rare and often limited to research purposes. As current practice in mental health rarely stresses the importance of patients' personal resources, the feasibility of strengths-based assessments has rarely been validated within such a population. We designed a new instrument, the Strengths Q-sort Self-Assessment Scale, aimed at identifying patients' strengths profile. This new scale measures 30 strengths classified in three sections: (i) personal characteristics, (ii) hobbies/passions, (iii) environmental/social strengths. In order to be adjusted for patients with cognitive or language impairments, this instrument is based on a Q-Sort method with figurative items. The aim of this study was to test the feasibility and acceptability of this scale in a sample of 21 psychiatric patients. Preliminary results showed that this tool can easily be administered and is well appreciated by patients. Feedback from clinicians highlight the benefits of identifying the strengths profiles in order to help defining realistic shared clinical objectives based on patients' strengths.
\end{abstract}

Keywords Strengths assessment $\cdot$ Recovery $\cdot$ Psychiatric patients $\cdot$ Well-being $\cdot$ Positive psychology

T. Bellier-Teichmann $(\bowtie) \cdot$ V. Pomini

Institute of Psychology, University of Lausanne, Quartier

Mouline, Geopolis, Bureau numéro 4109, 1015 Lausanne,

Switzerland

e-mail: tanja.bellier@unil.ch
The domain of clinical psychology traditionally aims at alleviating suffering and reducing negative emotions such as sadness, fear or exaggerated anger. Symptoms as well as patients' difficulties and needs are now empirically conceptualized and measured (Wood and Joseph 2010). Empirically validated treatments exist for an important number of mental disorders (Sanderson 2003). If deficitoriented assessment has improved the treatment of an important number of psychopathologies, it also has created a negative bias tending to reduce patients to diagnostic categories and considering strengths as peripheral (Rashid and Ostermann 2009).

Consumer movements, in response to the limits of current pharmacological or psychological therapies have led patients and professionals to adopt another conceptualization of recovery (Slade et al. 2008). This conceptualization gives great value to personal well-being and quality of life, despite the presence of symptoms or deficits related to the mental condition (Davidson and Roe 2007). Therefore, the latter does not consider the reduction or elimination of symptoms as the central point of recovery. Indeed, happiness or growth are not only definable as the absence of depression, anxiety, exaggerated anger, impulsivity or psychotic symptoms, but also as the presence of a number of positive emotional and cognitive states, such as optimism, self-confidence and positive identity (Slade 2009). Well-being is a process, which is over and above the absence of negative emotions, dysfunctional thoughts or maladaptive behaviors (Keyes 2009).

Moreover, evidence suggests that concentrating on strengths and well-being serves a preventative function against future psychopathology and relapse (Fredrickson 2001; Watson and Naragon-Gainey 2010; Wood and Joseph 2010). Seligman (2011) argues that pursuing one's characteristic strengths-the highest personal 
strengths-leads to more positive emotion, more meaning, and more accomplishment, as well as to better relationships. According to Csikszentmihalyi (1997) the self-awareness and use of personal strengths leads to an increase of engagement and flow states, which are intimately related to a sense of well-being and happiness. Indeed, a strengths-based approach to mental health care is not a new concept and has been largely spread by professionals in social work practice and occupational therapy (Saleebey 2006). Additionally, psychotherapy research has shown that focusing on patients' strengths can initiate and maintain a positive working alliance, increase patients' receptiveness to therapeutic interventions, and support the implementation of adaptive coping strategies (Flückiger et al. 2009). According to Grawe (1997), psychotherapy can only work with patients' talents and motivational readiness to change.

Consequently, a therapeutic strategy aimed at patients' recovery should not be related only to an exhaustive investigation of symptoms and needs, but also linked with patients' internal and external strengths (Rapp and Goscha 2006). Furthermore, it has been argued that the process of doing a strengths-based assessment is in itself therapeutic (Graybeal 2001).

Practitioners admit the important role of positive functioning for their patients' well-being. However, they usually remain focused in their practice on the presence and intensity of psychopathology, dysfunctional behaviors, thoughts or emotions, and therefore use instruments measuring mainly symptoms and deficits (Shankland and Martin-Krumm 2012). Even in the clinical examination and history taking, psychiatry handbooks mainly put the emphasis on problematic points, neglecting to steer attention to positive life episodes and qualities of the person or his/her family (e.g. Puri and Treasaden 2011). Therefore, the vast majority of clinical instruments used in a mental health setting rarely measure the nature or degree of patients' strengths.

We reviewed some existing instruments in order to select one that could easily be adapted to current practice in psychosocial rehabilitation, psychiatry or psychotherapy. Such an instrument should meet some basic requirements in order to improve the chances of its use in clinical routine: it should be simple, brief, relevant and useful in the eyes of its users (patients and multidisciplinary staff). We present here four instruments, which were likely candidates. We also present the development of a new assessment, which we consider as hopefully responding better to our expectations and aims, which were the following: measuring a profile of adult psychiatric patients' strengths, particularly adapted to people suffering from severe and chronic mental illness.

\section{Current Strengths Assessment Instruments for Clinical Use}

As stated by Joseph and Wood (2010) or Lopez and Snyder (2003), a number of scales, inventories and interviews measure positive functioning. Clinicians may opt for validated standardized instruments assessing patients' specific strengths. However, these instruments generally measure only one specific feature of positive human functioning (e.g. the level of self-esteem, hope, optimism, gratitude). They do not provide a general profile of the person's strengths.

Bird and colleagues completed in 2012 the only systematic review of strengths assessments profiles for use within mental health populations. These authors identified 12 different strengths assessments profiles (7 qualitative and 5 quantitative assessments). After reviewing the evaluative research as well as the psychometric properties of these existing strengths assessments, they concluded that only two of these could be recommended for routine clinical use: (1) The Strengths Assessment Worksheet (Rapp and Goscha 2006), and (2) The Client Assessment of Strengths, Interests and Goals (CASIG; Wallace et al. 2001).

However, none of these scales have been validated carefully enough to be sure that they are useful and adapted for patients suffering from severe and chronic mental illnesses. Issues for routine clinical practice, comprising the need on staff time and patients' ability to understand the assessments, were also overlooked (Bird et al. 2012).

\section{The Strengths Assessment Worksheet (SAW; Rapp} and Goscha 2006)

This instrument is the most widely utilized qualitative assessment within mental health settings (Bird et al. 2012). Its structure appears relatively complex, because it crosses seven life domains (daily life, finances, work/education, social support, health, leisure and spirituality/culture), with three temporal orderings (past, present and future) and four types of strengths. These latter are (1) the individual's personal qualities or characteristics, (2) his or her skills or talents, (3) the environmental strengths, and (4) his or her interests, passions or aspirations. This fourth strength is of particular importance, because a goal is more likely to be achieved if the person shows passion and interest towards it. This intrinsic motivation may be the strength that maintains the person throughout his or her personal recovery (Slade 2009). The SAW, however, provides only qualitative results, thus limiting its use for research or statistical purposes. It does not deliver profiles facilitating the comparison in between psychiatric patients. 
The Client Assessment of Strengths, Interests and Goals (CASIG; Wallace et al. 2001)

The CASIG presents strong psychometric properties, with good internal consistency, construct and content validities (Bird et al. 2012; Lecomte et al. 2004). It is based on a structured interview with open and closed questions that survey the individual's goals for improvement in six areas of community functioning, namely goals, current functioning, medication practices, quality of life and treatment, symptoms, and community behaviors. More specifically, the questions of the CASIG cover a large variety of dimensions classically used in needs assessments, such as living place, finances and work, interpersonal relationships, spirituality, health management, money management, nutrition, transportation, friends, leisure, hygiene, medication, side effects, rights, cognitive difficulties, symptoms, etc. As the SAW, the structure of this instrument is rather complex. It includes a number of various different dimensions, which cannot be considered as strengths (e.g. goals, symptoms or unacceptable community behaviors).

\section{Other Strengths Assessments}

One of the most commonly used strengths profile in the domain of positive psychology is the Values in ActionInventory of Strengths (VIA-IS) developed by Peterson and Seligman (2004). This is a 240 -item self-report questionnaire measuring 24 internal strength dimensions considered as universally accepted virtues of human beings (e.g. creativity, curiosity, love of learning, open-mindedness, bravery, persistence, social intelligence, fairness, leadership, gratitude, humor, etc.) This questionnaire focuses only on internal strengths without assessing external strengths. Good psychometric properties have been reported when used in the general population (Peterson and Park 2004). However, a lack of evidence was reported for any measurement properties when used within mental health services (Bird et al. 2012).

Dick (2003) proposed a Resource Checklist as a strength assessment instrument adapted to psychiatric patients. It consists of 50 items measuring 14 different life domains. Two types of resources are distinguished: the resources related to the person (feeling of being healthy and alive, self esteem, social competence and extraversion, capacity to build relationships and live, courage, creativity, feeling of control, serenity and trust, spirituality), and the external resources (marital status, family and friends, work and standard of living, leisure, living place). This evaluation can either be used as a self- or informant report. The aim is to use this questionnaire to support a resource-oriented interview with the patient. However, the psychometric properties of this instrument have not been tested.
None of the reviewed instruments completely satisfied our expectations. The SAW is limited to qualitative results. Regarding the CASIG, no study tested the good understanding of items by chronic psychiatric patients. The VIAIS is too long and not well suited to clinical use. Dick's Checklist covered a large profile of internal and external strengths. However, as it relies only on a verbal questionnaire, it does not appear well adapted to patients with cognitive or verbal impairments and unable to concentrate. Trauer and colleagues showed with the Camberwell Assessment of Need Short Schedule-Patient version that chronic psychiatric patients experience difficulties when completing even simple questionnaires (Trauer et al. 2008). Our experience in this domain led us to develop a Q-sort method using cards in order to bypass difficulties in selfassessing items on Likert scales (Pomini et al. 2008). Using this method for difficulties and needs self-assessment provided good results. Patients appreciated this original, concrete and somewhat playful way of investigating their problems and needs. Clinical staff trained with this instrument are usually also convinced of the benefits of the method (Pomini et al. 2008). We therefore decided to use the same methodology to develop a specific tool assessing patients' strengths.

\section{The Strengths Q-Sort Self-Assessment Scale (SQSS)}

The Strengths Q-sort Self-assessment Scale was developed having three main requirements in mind: (1) it should be simple and quick (no complex training needed to use it, and adapted to patients with chronic cognitive and language difficulties); (2) it should cover the major internal and external resources or strengths identified in scientific literature, (3) it should provide a general profile useful for planning psychosocial or clinical interventions and treatment. We defined strength as any internal or external element that may improve the person's quality of life or wellbeing. We wanted to limit the instrument to 25-40 items, each of them formulated with one or two words summarizing a set of more specific resources.

Considering the various models of resources and strength conveyed by the existing instruments (e.g. internal versus external resources by Dick (2003); 4-dimensional strengths model by Rapp and Goscha (2006), 24 internal strengths by Peterson and Seligman (2004), we conducted iterative rounds of brainstorming in order to generate and select items relying on extensive literature searches about strengths assessments and models. Dozens of candidate strengths were identified and discussed to be considered for inclusion within the classification of this strength profile. A pool of fifty items was firstly assessed with five psychiatric patients in order to check: (1) how redundant these items 
Table 1 Items covered by the strengths Q-sort self-assessment scale

\begin{tabular}{|c|c|c|}
\hline $\begin{array}{l}\text { Qualities and } \\
\text { personal } \\
\text { characteristics }\end{array}$ & Hobbies and passions & $\begin{array}{l}\text { Environmental and } \\
\text { social strengths }\end{array}$ \\
\hline 1. Humor & 1. Doing sports & 1. Family \\
\hline 2. Self-esteem & 2. Cooking & $\begin{array}{l}\text { 2. Romantic } \\
\text { relationship }\end{array}$ \\
\hline 3. Courage & $\begin{array}{l}\text { 3. Singing/playing an } \\
\text { instrument }\end{array}$ & 3. Friends \\
\hline 4. Curiosity & $\begin{array}{l}\text { 4. Painting/drawing/ } \\
\text { taking photographs/ } \\
\text { Creating }\end{array}$ & $\begin{array}{l}\text { 4. Neighbors/ } \\
\text { colleagues/ } \\
\text { acquaintances }\end{array}$ \\
\hline 5. Perseverance & $\begin{array}{l}\text { 5. Being with/talking } \\
\text { with friends }\end{array}$ & 5. Work \\
\hline $\begin{array}{l}\text { 6. Enthusiasm/ } \\
\text { wonder/savoring }\end{array}$ & 6. Reading/writing & 6. Living place \\
\hline $\begin{array}{l}\text { 7. Body } \\
\text { consciousness }\end{array}$ & $\begin{array}{l}\text { 7. Gardening/home } \\
\text { repair }\end{array}$ & $\begin{array}{l}\text { 7. Professional } \\
\text { healthcare }\end{array}$ \\
\hline 8. Reflectiveness & $\begin{array}{l}\text { 8. Listening to music/ } \\
\text { going to a show }\end{array}$ & 8. Pet \\
\hline 9. Optimism & 9. Travelling & $\begin{array}{l}\text { 9. Other } \\
\text { environmental or } \\
\text { social strengths }\end{array}$ \\
\hline 10. Gratitude & $\begin{array}{l}\text { 10. Playing games/ } \\
\text { surfing the Internet }\end{array}$ & \\
\hline 11. Hope & $\begin{array}{l}\text { 11. Other hobbies/ } \\
\text { passions }\end{array}$ & \\
\hline \multicolumn{3}{|l|}{ 12. Spirituality } \\
\hline $\begin{array}{l}\text { 13. Other personal } \\
\text { characteristics }\end{array}$ & & \\
\hline
\end{tabular}

could be, (2) how easily they were understood by the patients and perceived by them as strengths related to recovery.

At the end of this first step, the SQSS was limited to 30 items classified in three categories (see Table 1): (1) personal qualities and characteristics, (2) leisure activities or passions, (3) environmental or social strengths. This structure based on three categories is adapted from Rapp and Goscha's (2006) strengths model, where we merged skills/talents and interests/ passions/aspirations in one category (leisure activities or passions). It is also compatible with the two-dimensional model of Dick (external and internal resources).

The first category includes 12 character strengths (see Table 1) and was mainly inspired by the list of character strengths defined in the VIA (Peterson and Seligman 2004). We decided to exclude any item not directly related to recovery or not easily understood by the patients. For example "Leadership" was wrongly interpreted by some patients as synonymous to authoritative behavior, and then negatively valued. We added also items suggested by Rapp and Goscha (2006) or Dick (2003) (e.g. Self-esteem, Enthusiasm/Wonderment/Savoring, Body consciousness) which were not present in the VIA. We added a blank card to allow the patients mentioning other strengths that do not appear in our list. This facilitates an individual adaptation to each specific patient according to his or her personal strengths.

The second category lists a series of hobbies or passions, which a person may have. As noted by Arnold (1997), less than a third of people have a good knowledge of their personal strengths. Psychiatric patients with a low selfesteem may suffer from a lower capacity to identify and be aware of their personal strengths. Therefore, we acknowledged the benefits of measuring more concrete and easily identifiable aspects. Moreover, doing frequently leisure activities heightens the presence and the accessibility of positive emotions (Tugade and Fredrickson 2007). We based our selection of hobbies on a leisure list (Linehan 1993) and grouped together activities of the same nature (e.g. sports = skiing, swimming, running, playing tennis, etc.). Ten hobbies or passions were finally selected, again with a blank card in order to add hobbies or passions not present in the set of cards.

The third category gathers external resources within the immediate environment and wider community. This third category is inspired by research evidence indicating that social support affects mental and physical health (Ganster and Victor 2011). We included here all the important relationships or contexts in which an individual can build his or her well-being (e.g. family, romantic relationships, friends, pets, work, etc.). We also added a blank card for this third category.

The material of the SQSS are cards. Each of them displays the name of one strength associated with a picture symbolizing it. The pictures form a concrete support on which clinicians and patients rely in order to orient a strength-based assessment and discussion. The pictures were chosen after a pre-test where individuals had to connect a series of pictures with the selected strength dimensions. The picture most frequently associated with one corresponding strength was retained.

Completing the Q-sort involves three different steps, where patients are asked to sort and rank the cards according to specific instructions. This process allows obtaining the same results as scoring the items in dichotomous variables or Likert scales. In each step a new dimension is explored: (a) the presence/absence of strengths, (b) the degree to which present strengths contribute to personal well-being, (c) the wish to develop new strengths. This last Q-sort is similar to a measure of needs/goals. The measure quantifies whether the patient wishes to develop internal or external strengths. This is different from reducing or eliminating problems or symptoms as it is often measured in needs assessments. In that sense, the absence of a specific strength does not equal the presence of a difficulty in the patients' life. 
A. Which strengths are:

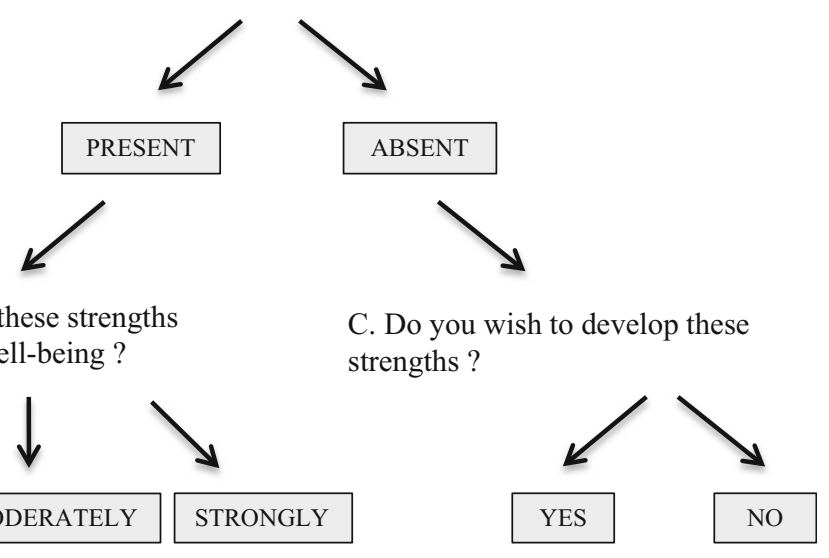

Fig. 1 Administration of the SQSS: Q-sort steps

This three-step sorting procedure is separately repeated for each category of strengths. Concretely, patients go throughout the same Q-sort process for each group of resources (see Fig. 1). Firstly, they assess the current presence or absence of each strength in their life. Secondly, they evaluate the degree of contribution to their well-being of each present strength. Therefore, they classify the cards of their present strengths into four piles (none, slight, moderate or strong contribution). Thirdly, they sort out the discarded cards (this means the absent strengths) by dividing them into two groups differentiating between: absent strengths they wish to develop and absent strength they do not want to develop.

After the Q-sort assessment, a semi-structured interview is conducted with the patient allowing the identification and exploration of his or her existing strengths. The clinicians ask the patients the following questions: How do you use these chosen strengths in your everyday life? In which concrete and specific situations do you use them? How do these strengths facilitate your well-being and recovery? In which ways would these new strengths be useful in your life?

The time used for the total administration of the strengths profile varies between 45 and 90 min when used in a clinical context. For research purposes, administration can take $20 \mathrm{~min}$ if the qualitative phase is not explored or drastically limited to specific questions. Currently there is no manual for conducting the semi-structured interview in both clinical and research contexts. Specific questions in both settings would clearly be different.

A scoring sheet allows the clinician to report the patients' classifications for the three categories (see Table 2). The final scores can be transformed into a chart form giving the clinician a visual synthesis of the patient's strengths profile for each category. The number of present strengths, their average contribution to well-being, as well
Table 2 Example of scoring sheet

\begin{tabular}{|c|c|c|c|}
\hline $\begin{array}{l}\text { Qualities and personal } \\
\text { characteristics }\end{array}$ & Presence & $\begin{array}{l}\text { Contribution to } \\
\text { well-being }\end{array}$ & Development \\
\hline 1. Humor & 1 & 4 & \\
\hline 2. Self-esteem & 0 & & 1 \\
\hline 3. Courage & 1 & 2 & \\
\hline 4. Curiosity & 1 & 1 & \\
\hline 5. Perseverance & 0 & & 0 \\
\hline $\begin{array}{l}\text { 6. Enthusiasm/wonder/ } \\
\text { savoring }\end{array}$ & 1 & 4 & \\
\hline 7. Body consciousness & 1 & 3 & \\
\hline 8. Reflectiveness & 0 & & 1 \\
\hline 9. Optimism & 1 & 3 & \\
\hline 10. Gratitude & 1 & 2 & \\
\hline 11. Hope & 0 & & 0 \\
\hline 12. Spirituality & 1 & 4 & \\
\hline $\begin{array}{l}\text { 13. Other personal } \\
\text { characteristics }\end{array}$ & 0 & & 0 \\
\hline Total & 8 & 23 & 2 \\
\hline
\end{tabular}

Presence: Absent $=0 /$ Present $=1$, Contribution to well-being: Not at all $=1 /$ Slightly $=2 /$ Moderately $=3 /$ Strongly $=4$, Development: Absent $=0 /$ Present $=1$

as the number of strengths patients wish to develop can be calculated for statistical use.

\section{Pilot Study}

The process leading from the elaboration of the tool to its validation is a lengthy one. This paper presents the results of a pilot study, whose aim was to test whether this tool was adapted to psychiatric patients. We also wanted to verify how those psychiatric patients perceived and understood the three Q-sort tasks as well as their associated 
semi-structured interviews. Before engaging in a more ambitious validation study, we first wanted to test and report the feasibility of the SQSS on a small sample of psychiatric patients. Furthermore, as these types of strengths profiles are rarely used in clinical contexts, we also wanted to check whether the profiles obtained give clinicians worthwhile indications for their daily clinical work. Therefore, the administration of the SQSS was carefully documented and followed by a semi-structured interview exploring how the patients experienced this new instrument.

\section{Sample}

The study was approved by the National Health Service Research Ethics Committee and was carried out in two mental health centers of the Department of Psychiatry of the University Hospital in Lausanne, Switzerland: (1) a case management program preparing discharge from hospital; (2) an outpatient mental health center specialised in psychiatric rehabilitation. Participants were recruited between August 2013 and February 2014 through referrals from ten health professionals. Some patients also came spontaneously after having heard about our strengths assessment. Inclusion criteria were (a) being between the ages of 18 and 70, (b) meeting DSM-V criteria for a psychiatric diagnosis, (c) having sufficient skills in French to understand the items. Exclusion criteria were (a) persons incapable of discernment, (b) organic mental disorders and (c) severe decompensation impeding the strengths assessment. Clinicians verified whether each patient corresponded to the criteria of the study. In this pilot study, there was no case of exclusion. The overall sample includes 21 patients with a mean age of 43.36 $(\mathrm{SD}=10.03)$. The characteristics of the study sample were the following: we included 11 women and 10 men. 11 were single, 6 married and 4 divorced or separated. 10 patients were living alone, 10 with partner or family and 1 in a supervised housing. 12 patients had no professional activity, 8 were working in sheltered workshops and 1 had a part-time job. The diagnoses were the following: 8 patients were suffering from schizophrenia, 7 from mood disorders, 2 from neurotic and anxiety disorder, 2 from personality disorder and 2 from mental disorders due to psychoactive substance use.

Patients' Attitudes During the Administration of the SQSS and Personal Views Regarding the Scale

The 21 patients were able to sort and rank the cards autonomously and without much intervention from the clinician. All the patients understood the procedure in three steps. The duration of the assessment did not seem to exceed the capacity of patients' concentration. There were neither refusals nor interruptions during the test.

Patients were systematically asked about the weaknesses and strengths of this assessment. The first impressions and feedback from the 21 patients were positive. The majority pointed out that this strength assessment was interesting, pleasant and useful. The tool helped them to discover-or at least to become more aware of-personal characteristics or external resources. Only one patient questioned the usefulness of this assessment, as he was already quite aware of his personal strengths. Two of them expressed difficulties in identifying and classifying their personal characteristics. It was easier for them to identify their hobbies or passions, as well as their environmental or social strengths. The benefits mentioned by patients were the following: this tool helped them to identify their personal resources, and to stimulate their willingness to develop new strengths. One patient described it the following way: "I always thought that I have poor self-esteem and that this is it. I won't change anything about it. As I saw your card and the possibility of putting it into the "I want to develop" pile, I suddenly became aware that I could still change this, work on and increase my selfesteem." Another important benefit of this assessment was the help in accepting absent strengths dimensions. One patient explained it as follows: "I have a dysfunctional family, I have been fighting for years hoping they will support me more. Thanks to this assessment, I realized that having a supportive family is an absent dimension or strength in my life. The best thing I can do about it is to accept this." More generally, patients mentioned that this tool helped them to reflect back on their lives and bring new and useful insights for their recovery or psychosocial rehabilitation.

\section{Clinicians' Perspective}

The ten clinicians who referred their patients were asked about the benefits and weaknesses of this strengths profile. After each strengths assessment, we transmitted the clinicians the scoring sheet as well as the charts of their patients' strengths. This included the quantitative as well as the qualitative results of the strengths interview. The individual results were discussed between the clinicians and the psychiatric patients. Clinicians and psychotherapists acknowledged the usefulness of obtaining the strengths' profiles of their patients. These profiles were helpful for them in order to define new objectives and intervention strategies promoting patients' well-being and recovery. They suggested one change in order to improve this strengths profile. In this pilot version, we presented only cards of absent strengths for the third Q-sort. We asked the patients whether they wanted to develop these 
Table 3 Cumulative frequencies of strengths considered as (1) present, (2) absent and desirable (strengths patients want to develop). Mean contribution to well-being for each strength
Mean contribution to well-

being: Not at all $=1$ /

Slightly $=2 /$ Moderately $=3 /$

Strongly $=4$

\begin{tabular}{|c|c|c|c|c|}
\hline & $\begin{array}{l}\text { Present } \\
\text { strength }\end{array}$ & $\begin{array}{l}\text { Lacking but desirable } \\
\text { strength }\end{array}$ & $\begin{array}{l}\text { Mean } \\
\text { contribution }\end{array}$ & $\begin{array}{l}\text { Standard } \\
\text { deviation }\end{array}$ \\
\hline Humor & 17 & 3 & 3.24 & 0.94 \\
\hline Self-esteem & 6 & 15 & 3.33 & 0.47 \\
\hline Courage & 9 & 9 & 3.00 & 0.82 \\
\hline Curiosity & 17 & 1 & 3.06 & 0.94 \\
\hline Perseverance & 13 & 8 & 3.31 & 0.72 \\
\hline Enthusiasm/wonder/savoring & 10 & 7 & 3.30 & 1.00 \\
\hline Body consciousness & 13 & 5 & 2.85 & 0.95 \\
\hline Reflectiveness & 14 & 6 & 2.57 & 0.90 \\
\hline Optimism & 13 & 7 & 3.31 & 0.61 \\
\hline Gratitude & 19 & 0 & 3.11 & 1.07 \\
\hline Hope & 8 & 7 & 3.63 & 0.70 \\
\hline Spirituality & 7 & 3 & 2.86 & 0.64 \\
\hline Sports & 9 & 7 & 3.33 & 0.94 \\
\hline Cooking & 9 & 8 & 2.67 & 1.15 \\
\hline Singing/playing an instrument & 11 & 4 & 2.91 & 1.00 \\
\hline Plastic arts & 13 & 3 & 3.08 & 1.07 \\
\hline Being with/talking with friends & 12 & 3 & 3.67 & 0.62 \\
\hline Reading/writing & 14 & 3 & 3.14 & 1.12 \\
\hline Gardening/home repair & 9 & 4 & 2.89 & 0.74 \\
\hline Music/shows & 16 & 3 & 2.88 & 0.78 \\
\hline Travelling & 2 & 11 & 4.00 & 0.00 \\
\hline Playing/internet & 16 & 1 & 2.31 & 0.92 \\
\hline Family & 13 & 2 & 3.38 & 0.74 \\
\hline Romantic relationship & 8 & 8 & 3.63 & 0.48 \\
\hline Friends & 11 & 9 & 3.55 & 0.66 \\
\hline Acquaintances & 14 & 3 & 3.00 & 0.76 \\
\hline Work & 5 & 10 & 3.80 & 0.40 \\
\hline Living place & 18 & 2 & 2.89 & 1.24 \\
\hline Professional healthcare & 21 & 0 & 3.62 & 0.90 \\
\hline Pet & 8 & 4 & 3.38 & 0.86 \\
\hline
\end{tabular}

Firstly, all the items were selected as present strengths by at least eight patients, except travelling $(n=2)$, work $(n=4)$, self-esteem $(n=6)$, and spirituality $(n=7)$. Some items were even chosen by almost all the patients: healthcare services $(n=21)$, gratitude $(n=19)$, living place $(n=18)$. Humor and curiosity $(n=17)$, playing/ surfing on the Internet as well as listening to music/going to shows $(n=16)$ were also considered by most of the patients as present strengths.

Exploring each category of strengths separately, we notice that patients selected gratitude, sense of humor and curiosity as the most prevalent personal characteristics. Self-esteem, spirituality, hope and courage were the most absent strengths in the profiles (Table 3). Interestingly hope and self-esteem are two important active factors in the recovery process (Andresen et al. 2003). These types of 
strengths might be more present in patients suffering from less chronic or less severe mental disorders.

Regarding the second category of strengths, playing/ surfing the internet, listening to music followed by reading/ writing were the most present hobbies. As already mentioned, only travelling was very infrequently mentioned as present $(n=2)$. Nevertheless, eleven persons considered this passion as desirable and wished to be able to travel. This surely translates the current cultural and socio-economical contexts of our patients, who cannot practice some hobbies or passions because of limited financial means. Concerning the third category, the sample profile highlighted healthcare services $(n=21)$ as well as the living place $(n=18)$ as being the most present environmental or social strengths, before acquaintances $(n=14)$, family $(n=13)$ and friends $(n=11)$. This result recalls the important role of social support for people's welfare. Work $(n=5)$, pet and romantic relationships $(n=8)$ were less cited as present strengths.

If we now turn our attention to the strengths patients did not want to develop, we can observe that only few strengths have been judged as useless for personal well-being. Pets appeared nine times (as a strength patients did not want to develop); travelling and gardening eight times; hope, being with friends, playing music, work and family six times. At the other end, perseverance and self-esteem were never viewed as useless for personal well-being; whereas reflectiveness, sense of humor, optimism, friends and living place appeared only once as useless. Nevertheless, we have to remain cautious with these frequencies because of the small size of the sample.

For this instrument to demonstrate clinical utility, there is no assumption that every item should be checked at least by a third or a quarter of the psychiatric population, but very infrequent items do not bring sufficient information and can lead to a decision to discard them. In our opinion, however, this type of reflection is perhaps only applicable to the travelling item, because the other dimensions appear as theoretically too important in the conceptualization of patients' strengths and recovery. Therefore, they cannot simply be eliminated because they are not sufficiently chosen in a pilot study. The vocational dimension is too crucial in the rehabilitation practice; similarly, self-esteem appears as extremely important in the recovery process. Indeed, self-esteem was always defined as a desirable strength patients want to develop when absent. The fact that spirituality is chosen as present or desirable only for a small half of the patients seems to correspond to a clinical reality, whereby this dimension cannot be considered as helpful for every person. The most present hobbies and passions are the ones that can be practiced without spending too much money. Patients, especially youngsters, also have an easy access to Internet, video games and music. Again, although such strengths are not particularly interesting from a statistical point of view (because of the poor variance associated with them), they appear important from a clinical perspective. A frequently mentioned strength has a good probability of also being a strength for a single patient in clinical consultation.

Regarding the mean contribution of each strength to the patients' well-being, our results showed that if a strength was present, it contributed on average moderately to strongly to the patients' well-being. Our results tend to confirm the importance of separating the measure of frequency of a strength (presence vs absence) from its contribution to well-being. Indeed the mean contributions showed that more present but less active hobbies (e.g. listening to music and playing/surfing the Internet) were not perceived as contributing to personal well-being as much as more active but less present strengths (e.g. talking with friends, sports, reading/writing). This measure helps the patient and the clinician to become more aware of which specific strengths contribute the most to each patient's personal well-being. These specific strengths can then be stimulated through psychotherapy in order to be activated in particular adverse life situations.

\section{Conclusion}

Psychosocial evaluation has to meet a dual requirement (Lecomte et al. 2004). The first consists in exhaustive documentation and comprehensive understanding of the psychosocial functioning of psychiatric patients, their psychopathologies as well as their strengths. Scientific standards comprise the development of instruments sensitive to change and with satisfactory psychometric properties. The second requirement is a clinical and practical one inspired by a recovery-centered practice. This means developing strengths instruments adapted to the specificities of psychiatric patients, as well as centered on the patients and their expertise. Strengths-based assessments should have a mobilizing function, which reinforce or develop patients' dreams and recovery projects. Identifying personal strengths can facilitate a redefinition of one's identity and contribute to meaning in life, hope and the ability to take responsibility for one's life.

The SQSS aimed at satisfying these two requirements in a psychosocial evaluation: (1) a measurement of strengths assessing a large profile of patients' internal and external strengths. (2) a self-evaluation based on the patients' expertise and having a mobilizing effect. Therefore, this strengths profile is intended to be motivating and mobilizing for the development of a recovery project. It should also nurture or restore hope and responsibility in psychiatric patients. 
The current pilot study, representing a preliminary step, involved a first test of the feasibility of this strength assessment with psychiatric patients. As Bird et al. (2012) mentioned in their systematic review of strengths assessments, no feasibility studies have yet been conducted within mental health services.

This study showed that this instrument was generally adapted to psychiatric patients' specificities. All 21 patients were able to sort out and rank the cards autonomously. Our first experience and results with this new strengths profile are promising. The feasibility of this method has been demonstrated.

Furthermore, the first impressions and feedback from patients and clinicians were positive. This instrument was well accepted and appreciated by all of the psychiatric patients. Moreover, patients stated that this instrument was useful in terms of identifying their personal strengths and using them in their everyday life, as well as identifying their wishes to develop new strengths in order to potentially access a richer, more fulfilling and meaningful life. The patients enjoyed becoming more aware of their personal strengths and qualities. They also expressed gratitude for the external strengths they noticed in their life. Patients perceived this assessment as a driver of change in order to develop new strengths.

The clinicians suggested using all the strengths dimensions - even present strengths-for the Q-sort in which we ask the patients which strengths they wish to develop. It appeared indeed that some strengths were present in the patients' lives but infrequently used in their everyday life. This can be related to the aware-explore-apply model developed by Niemiec (2013). This author suggested a process in three steps increasing the use of personal strengths. The first step consists in identifying personal strengths, i.e. (a) strengths-spotting (b) combating strengths blindness and (c) cultivating strengths awareness. The second step involves exploration: (a) exploring strengths' overuse and underuse, (b) using across contexts and (c) exploring past use in relation to problems and successes. The third step includes the use of these strengths. This means: (a) taking action with goal-setting, (b) deploying and aligning strengths. Our new strengths assessment allows identifying and exploring patients' strengths. Using the third Q-sort ("do you wish to develop new strengths?") with all the cards of this assessment could facilitate the third step consisting in the deployment and development of existing as well as new personal strengths.

Although the methods and administration of the strengths profile proved feasible, there are restrictions on the ability to generalize the results of this research. Based upon these factors, several directions for future research are worth considering. Further steps will involve a validation study on a larger sample of adult psychiatric patients. A larger-scale study including a larger sample of psychiatric patients will shed additional light on the issue of psychiatric patients' strengths as well as on the validity of this strengths profile. Another interesting step will be the measurement of the impact of patients identifying their personal strengths. The SQSS shows promise in promoting further dialogue between mental health care professionals and their patients. This dialogue would further foster a focus on patients' self-identified strengths and areas for development of new strengths.

\section{References}

Andresen, R., Oades, L., \& Caputi, P. (2003). The experience of recovery from schizophrenia: Towards an empirically validated stage model. Australian and New Zealand Journal of Psychiatry, 37, 586-594. doi:10.1046/j.1440-1614.2003.01234.x.

Arnold, J. (1997). Managing careers into the 21st century. London: Paul Chapman.

Bird, V. J., Le Boutillier, C., Leamy, M., Larsen, J., Oades, L. G., Williams, J., et al. (2012). Assessing strengths of mental health consumers: A systematic review. Psychological Assessment, 24, 1024-1033.

Csikszentmihalyi, M. (1997). Finding flow: The psychology of engagement with everyday life. New York: Basic Books.

Davidson, L., \& Roe, D. (2007). Recovery from versus recovery in serious mental illness: One strategy for lessening confusion plaguing recovery. Journal of Mental Health, 16, 459-470. doi:10.1080/09638230701482394.

Dick, A. (2003). Psychotherapie und Glück: Quellen und Prozesse seelischer Gesundheit [Psychotherapy and happiness: sources and processes of mental health]. Bern: Huber.

Flückiger, C., Caspar, F., Grosse Holtforth, M., \& Willutzki, U. (2009). Working with patients' strengths: A microprocess approach. Psychotherapy Research, 19, 213-223.

Fredrickson, B. L. (2001). The role of positive emotions in positive psychology: The broaden-and-build theory of positive emotions. American Psychologist, 56, 218-226.

Ganster, D. C., \& Victor, B. (2011). The impact of social support on mental and physical health. British Journal of Medical Psychology, 61, 17-36.

Grawe, K. (1997). Research-informed psychotherapy. Psychotherapy Research, 7(1), 1-19.

Graybeal, C. (2001). Strengths-based social work assessment: Transforming the dominant paradigm. Families in Society, 82, 233-242.

Joseph, S., \& Wood, A. (2010). Assessment of positive functioning in clinical psychology: Theoretical and practical issues. Clinical Psychology Review, 30, 830-838.

Keyes, C. L. M. (2009). Toward a science of mental health. In C. R. Snyder \& S. J. Lopez (Eds.), Oxford handbook of positive psychology (pp. 89-95). Oxford: University Press.

Lecomte, T., Wallace, C. J., Caron, J., Perreault, M., \& Lecomte, J. (2004). Further validation of the client assessment of strengths interests and goals. Schizophrenia Research, 66, 59-70.

Linehan, M. M. (1993). Skills training manual for treating borderline personality disorder. New York: Guilford.

Lopez, S. J., \& Snyder, C. R. (Eds.). (2003). Positive psychological assessment: A handbook of models and measures. Washington, DC: American Psychological Association. 
Niemiec, R. M. (2013). Mindfulness and character strengths: A practical guide to flourishing. Boston: Hogrefe.

Peterson, C., \& Park, N. (2004). Classification and measurement of character strengths: Implications for practice. In P. A. Linley \& S. Joseph (Eds.), Positive psychology in practice (pp. 433-446). Hoboken: Wiley.

Peterson, C., \& Seligman, M. E. P. (2004). Character strengths and virtues: A handbook and classification. Washington DC: APA Press.

Pomini, V., Golay, P., \& Reymond, C. (2008). L'évaluation des difficultés et des besoins des patients psychiatriques. Les échelles lausannoises ELADEB [Assessment of psychiatric patients' difficulties and needs. The Lausanne ELADEB scales]. L'Information Psychiatrique, 84, 892-902.

Puri, B. K., \& Treasaden, I. H. (2011). Textbook of psychiatry (3rd ed.). Edinburgh: Churchill Livingston.

Rapp, C., \& Goscha, R. J. (2006). The strengths model. Case management with people with psychiatric disabilities (2nd ed.). Oxford: University Press.

Rashid, T., \& Ostermann, R. F. (2009). Strengths-based assessment in clinical practice. Journal of Clinical Psychology, 65, 488-498.

Saleebey, D. (2006). The strengths approach to practice. In D. Saleebey (Ed.), The strengths perspective in social work practice (4th ed., pp. 77-92). Boston: Allyn \& Bacon.

Sanderson, W. C. (2003). Why empirically supported psychological treatment are important. Behavior Modification, 27, 290.

Seligman, M. E. P. (2011). Flourish. New York: Simon \& Schuster.

Shankland, R., \& Martin-Krumm, C. (2012). Evaluer le fonctionnement optimal: échelles de psychologie positive validées en langue française [Assessing optimal functioning: Positive psychology scales validated in French]. Pratiques Psychologiques, 18, 171-187.

Slade, M. (2009). The personal recovery framework. In M. Slade (Ed.), Personal recovery and mental illness: A guide for mental health professionals (pp. 77-93). Cambridge: Cambridge University Press.

Slade, M., Amering, M., \& Oades, L. (2008). Recovery: An international perspective. Epidemiologia e Psichiatria Sociale, $17(2), 128-137$.

Trauer, T., Tobias, G., \& Slade, M. (2008). Development and evaluation of a patient-rated version of the Camberwell Assessment of Need Short Appraisal Schedule (CANSAS-P). Community Mental Health Journal, 44(2), 113-124. doi:10.1007/ s10597-007-9101-z.

Tugade, M. M., \& Fredrickson, B. L. (2007). Regulation of positive emotions: Emotion regulation strategies that promote resilience. Journal of Happiness Studies, 8, 311-333.

Wallace, C. J., Lecomte, T., Wilde, J., \& Liberman, R. P. (2001). CASIG: A consumer-centered assessment for planning individualized treatment and evaluating program outcomes. Schizophrenia Research, 50, 105-119.

Watson, D., \& Naragon-Gainey, K. (2010). On the specificity of positive emotional dysfunction in psychopathology: Evidence from the mood and anxiety disorders and schizophrenia/schizotypy. Clinical Psychology Review, 30, 839-848.

Wood, A. M., \& Joseph, S. (2010). The absence of positive psychological (eudemonic) well-being as a risk factor for depression: A ten year cohort study. Journal of Affective Disorders, 122, 213-217. 